\title{
LA POESÍA EN LA ERA DE INTERNET
}

\author{
POETRY IN THE INTERNET AGE
}

\author{
Pablo JAURALDE POU \\ Universidad Pompeu Fabra \\ clasicoshispanicos@gmail.com
}

Resumen: Este artículo reflexiona sobre las implicaciones que tiene producir poesía en la era de la cultura digital y que incluye en diversos aspectos de la misma (creación, lectura, difusión, distribución...). Detiene la mirada en los cambios que la irrupción de las redes sociales ha traído consigo, de manera que podamos pensar en el cambio de paradigma que ha supuesto.

Palabras clave: Poesía digital. Redes sociales.

\begin{abstract}
This article reflects on the implications of producing poetry in the era of digital culture, which includes several aspects (creation, reading, dissemination, distribution...). It analyze the changes that the irruption of social networks has brought with it, so that we can think about the paradigm shift that it has supposed.
\end{abstract}

Key Words: Digital poetry. Social Networks. 
Mucha variedad de versos en la nueva era. Decían que a la época del libro y la lectura, a la cultura del libro, iba a suceder la cultura de la imagen; y algo de eso hay, pues entre las generaciones más jóvenes se observan movimientos que transforman el modo de conectar con los demás o con lo que pasa: el abandono de la televisión, el acceso individual a otros modos de comunicación —-fundamentalmente visuales-, el desarrollo galopante de la técnica en la carrera de las comunicaciones, haciendo añicos lejanías, distancias, tiempos, etc. en efecto nos encarrilan hacia esa nueva era, es indudable, con un matiz en el que yo sigo creyendo a pesar de todo: no desaparecerá la vieja cultura del libro y de la escritura, convivirá con las nuevas.

Sobre ese auge que acarrean los tiempos modelando conductas e ideologías actúan, a su vez, otros nada desdeñables que crecen a su amparo, fundamentalmente con los mismos fines: publicidad, mercantilismo, liberalismos, etc. En muchos casos, como veremos, degradan el campo que cultivan. Con todo eso tenemos lo que se podría llamar hoy "la cultura actual”, que a su vez se desarrolla de modo impar según qué comunidades, es decir, según se implante de una u otra manera, Por desgracia, en nuestro país, esa implantación se realiza de manera burda y torpe, probablemente para favorecer aún más a las clases privilegiadas — que manipulan el cotarro-y para entorpecer cualquier posibilidad de cultura real que abra el juicio crítico.

¿Qué lugar ocupan los versos en todo este tinglado? Los versos vienen colgados de una tradición que los ennoblece, probablemente que los falsea también, como sesgo personal que ennoblece individualmente a quien los practica. En realidad yo suelo defender la "creación", en este caso de versos, de poesía, como lugar en donde se espacia la libertad; es decir, como espacio libre al que se asoma el individuo para un "lo que me dé la gana"; pero eso es otro cantar.

De varias maneras aparece el creador y la criatura de versos en la nueva era digital de la cultura de la imagen. Una es para encarrilar hacia esos modos los viejos versos que constituyen nuestra tradición literaria: 
libros electrónicos, por ejemplo, o transmisión digitalizada de lo que hasta ahora era la vieja cultura escrita, acompañada o no de otros ingredientes (pintura, música, representación, fotos, dibujos, etc.). La otra es la aparición de versos y poesías en los llamados "círculos sociales", es decir, en el sistema de medios que sostienen en estos momentos la cultura de la imagen.

Cualquiera que frecuente esos lugares sabe de lo que estoy hablando. Los viejos géneros literarios hace tiempo que padecen o disfrutan de esa acometida que proviene de las necesidades de adaptarse a otro modo de transmisión. Esa es la razón por la que triunfa el microrrelato, como bien se sabe (cabe en una pantalla); o por la que proliferan los nuevos poetas que asoman a las llamadas redes sociales: todo el mundo quiere expresar "su intimidad", porque esa es la idea generalizada sobre la poesía.

Es curioso - y ya vamos a ir señalando peculiaridades de la nueva cultura escrita - los poetas consagrados, en su mayoría, no utilizan esos medios, ni para los versos ni, por supuesto, para otras modalidades de creación. Vamos, yo no he visto versos de las generaciones anteriores en los media, parece que hay una desvalorización "cervantina" en ese descenso a la divulgación o que — en muchos géneros - hay una defensa del copyright en el caso de relatos. Hace muy poco intenté editar en una colección electrónica un relato de Luis Landero... La editorial que tenía la exclusiva ni me contestó. Es lo normal.

Y sin embargo, sí que hay versos, bastantes versos, circulando de modo electrónico, on line; curiosamente son los más jóvenes (¿los no consagrados?) los que asoman allí, y algún poeta impenitente - como yo, que los escribo sistemáticamente- Pero ya empiezan a publicarse revistas, colecciones, etc. Hay como un choque generacional muy curioso entre los viejos poetas que consagró la cultura escrita y los nuevos que se sirven de la cultura de la imagen; en medio, como otras veces, cantautores y raperos; pero con esa misma característica, los consagrados no llevan a medios digitales más que lo que venden. Luego están las páginas oficiales, que son un elemento más de la propaganda, como las de Leonard Cohen, 
Bob Dylan, etc. que caben en el enorme compartimento de "publicidad", en donde todo se mezcla, verdades y mentiras, porque quien lo paga no es quien lo lee, sino quien publicita, matiz que, una vez más, contribuye a la degradación de la cultura de ese campo.

Quizá sea más interesante que observar el juego de olas que mueven a unos y otros centrarse en el tipo de poesía que asoma digitalmente. Hago de memoria un recorrido por algunos de los recursos habituales (facebook, blogs, twiter, instagram...). La tentación, casi siempre, es acompañar a los versos de otros ingredientes a los que se presta la digitalización, particularmente la presentación visual y la música. Si se trata de un híbrido de cultura escrita y cultura de la imagen su propia naturaleza parece que lo pide: y con esa forma se presenta abundantemente, más mejor con ilustraciones visuales (pintura, dibujo, películas, fotos, etc.) que con ilustraciones musicales, porque esas ya existían en otros géneros híbridos, como la ópera, el rap, o la canción del cantautor.

Es curioso, el canal de transmisión solicita ese acompañamiento, pero al mismo tiempo adelgaza la posibilidad de la entrega: a nadie se le ocurriría publicar una sección de un libro o un libro entero en una página de un blog o en una entrada de Facebook. Tampoco un poema extenso. Como en el caso de los microrrelatos, el canal impone una cierta contención expresiva del creador. Es bastante probable que todos tengan o hayamos tenido momentos fugaces de inspiración súbita, con un par de versos en el magín, que se pueden airear fácilmente, y a veces con éxito y aplauso. Muchos poetas, muchos momentos de creación, mucha brevedad. Es más difícil, complicado o sabe dios qué mantener esa inspiración a la larga, quizá; por eso podrían tener más valor los que consiguen sobrepasar esa inspiración súbita. En realidad, si uno se atiene a unos cuantos saberes técnicos - muy pocos y muy sencillos - se detecta enseguida quién es poeta de ocasión y quién oficia de poeta, aun cuando el "oficio" de poeta sea tan poco loable. La melodía de cualquier verso lo indica, de manera harto clara las más de las veces; y eso, para quien lo sabe, es un índice razonable para moverse en la selva de la poesía digital. 
Pero aún nos queda algo más que comentar. La naturaleza misma de los versos o del poema, ¿de qué modo se ve afectada por su propagación digital? Curiosamente, no se va más allá —y ya es mucho ir — de lo que era la poesía publicada en generaciones anteriores. Desde que Delaunay redacto el Transiberiano - ya superamos el siglo, estamos en 1912 - la poesía ha hecho todo tipo de piruetas consigo misma y en la página de un libro: ya no puede ir más allá más que desnaturalizándose, lo que también ha hecho, por cierto. Más allá está el laboratorio, al margen de la creación quizá.

Y ese es el panorama de la poesía digital actual, sobre el que me queda por añadir alguna cosa más. Quien esto escribe fundó, organizó y mantiene una colección de Clásicos Hispánicos en formato electrónico, que va por los 100 títulos, en donde está todo (Quijotes, Celestinas, Unamunos, Lorcas, etc. véase http://www.clasicoshispanicos.com/ [20/03/2018]) ¿De qué manera esa modalidad ha influido en los versos? Transgrediendo hábitos y maneras. Lo mismo se puede editar en un solo volumen todos los Episodios Nacionales que las Coplas de Jorge Manrique. El formato electrónico permite el acordeón en la presentación, la manejabilidad del repertorio clásico o moderno: lo mismo podemos editar una "loa" que una "parte" de comedias; un solo romance que toda la serie del romancero viejo. Quizá eso contribuya a apreciar y valorar de otra manera nuestro patrimonio literario. También hemos jugado a romper hábitos editoriales consagrados y poco fiables, como la edición con miles de notas que se llevan la creación a lejas tierras; o hemos desterrado a páginas impertinentes las variantes - para eruditos - o hemos controlado el prólogo o la introducción, como esos delantales de centenares de páginas que nos torturan antes de leer el Cántico Espiritual de San Juan de la Cruz... Bastantes cosas, desde luego.

La fugacidad de la imagen es una de las propiedades de la poesía y de los versos. Ocurre que cuando uno se asoma a una de esas ventanas, pantalla de por medio, el paso incesante de tiempo e imágenes es inexorable y los versos que leí ayer, por ejemplo, 24 horas después han quedado enterrados en la masa de noticias, como una cosa más, entre bromas, 
noticias, proclamas, curiosidades..., el almanaque condena al olvido los versos, a no ser que alguien quiera copiarlos y guardarlos: mi experiencia es que eso no ocurre. Como la vieja poesía efímera del barroco o como las canciones del juglar o como los romances del ciego. Parece normal, por tanto, que el vate, imbuido de tradiciones "inmortales", quiera preservar su creación y, si la entrega a la pantalla, además la conserve para publicarla, por ejemplo. Es una situación que se repite.

Si yo miro ahora, por ejemplo, la actualidad poética de Facebook, veo que aparecen poetas de muy diverso tipo, opinando en general (Ana Gorría, Francisco Díaz de Castro, Almudena Guzmán, Mercedes Cebrián, Benigno Domínguez Cuesta, Gema Palacios, Inés de la H, María do Cebreiro, Carlos Piera, Ángeles Mora, Pablo Casado...), pero no escriben versos, opinan sobre lo que va ocurriendo, algunos con opinión literaria. De vez en cuando se anuncia la presentación de un libro de poesía, en lugar ajeno (una librería, un café, etc. como la gira de Eduardo Espina, la presentación de Isabel Giménez Caro, los libros que presenta Sandro Luna, el colectivo que acaba de sacar Pablo Casado...). Y normalmente la pátina literaria, a veces poética, va asociada a alguna voz amiga (la invasora de Víctor Manuel Irún Vozmediano, la noble tarea de Juan Manuel Macías, que mantiene una buena revista en doble formato, digital y en papel; etc.) También ocurre que, de vez en cuando, se nos recuerdan versos conocidos o menos conocidos de poetas mayores o menores (Juan Antonio Masoliver, Piedad Bonnett, Félix Grande....), el recuerdo de Juan de Loxa. En esos momentos, se aprovecha el medio para centenarios, aniversarios y otras circunstancias.

En medio de este fragor encuentro poesía de Fati Zah, José Lapaz Romero, Bienvenido Morros (en catalán), Jose Manuel Lucía cita a Rosana Acquaroni, etc. En realidad hay pocas entradas centradas en creación poética. En este caso solo encuentro "Tribu de poetas...". Son mayores las mixtas, por ejemplo Lorca cantado por Emiliano Valdeolivas. Todo esto dependerá del círculo (“amigos") en el que uno se mueva, pero presumo que en mi caso podría ser representativo, en líneas generales. 
Un último ejemplo, el del libro anunciado de Pablo Casado, en Visor, con el bonito título de Estos días alegres y este sol de la infancia, que acaba de aparecer y aún no he leído. Asoma la publicidad, como dijimos, y las referencias nos señalan que es un libro colectivo en el que han intervenido muchos poetas de las hornadas recientes. Quisiera traerlo a colación, sin embargo, de cómo el rigor desciende en las páginas comunes de la cultura de la imagen, lo que no hubiera ocurrido de manera tan simple en el ámbito — viejo - de la cultura escrita. Ese título en un libro colectivo a Antonio Machado utiliza dos alejandrinos que, probablemente, nunca escribió Machado. Lo que pasa con esos versos se dijo (en el congreso de la AIH de Buenos Aires, hace años) y se ha publicado con detalle, como puede verse, entre otras, en ${ }^{1}$ :

- http://hanganadolosmalos.blogspot.com.es/2012/09/estos-diasazules-y-este-sol-de-la.html

- http://hanganadolosmalos.blogspot.com.es/2013/08/los-ultimos-versos-de-antonio-machado.html

- http://hanganadolosmalos.blogspot.com.es/2013/07/nuevoepisodio-en-la-batalla-de-los.html

Y esa coda nos sirve para introducir y acabar con un elemento más, el de las citas digitales, que todavía, sin duda, no han encontrado su formato, pues es un disparate emplear términos abstractos que nadie puede recordar.

Veremos a ver cómo se va moviendo todo.

Recibido el 15 de mayo de 2018. Aceptado el 28 de junio de 2018.

${ }^{1}$ Último acceso: 20/03/2018. 
